\title{
Supporting Parents of Aboriginal Children with Asthma: Preferences and Pilot Interventions
}

\begin{abstract}
Asthma is one of the most common chronic conditions affecting Aboriginal children and adolescents in Canada, with associated high rates of hospitalization and emergency room visits. Social support deficits and social isolation pose significant problems for Aboriginal families coping with asthma challenges. However, support interventions that focus on the unique support needs of parents of Aboriginal children affected by asthma have not been investigated. Consequently, our study introduced support interventions to meet parents' perceived support needs and intervention preferences. The study was conducted in urban and rural sites in three Canadian provinces. The interdisciplinary research team encompassed Aboriginal researchers and knowledge users, and the multimethod participatory research design was guided by Aboriginal community advisory committees. Diverse support interventions, designed to address the particular preferences and needs of parents in specific communities, were offered. Seventyseven parents participated. These parents reported expanded support resources, increased support seeking, improved coping skills, and decreased support and education needs following the interventions, which were tailored to their unique needs. These participatory interventions were considered accessible, acceptable, relevant, and useful by parents.
\end{abstract}

\section{Keywords}

Aboriginal, asthma, support, education, intervention, participatory, parents, children

\section{Authors}

Miriam Stewart, PhD, FCAHS, FRSC, held primary responsibility for research in the Alberta site and for article development and revisions. Heather Castleden, $\mathrm{PhD}$, performed data collection, analysis, and intervention implementation in the Nova Scotia site. Malcolm King, $\mathrm{PhD}$, was responsible for intervention design and guidance for the Alberta site. Nicole Letourneau, RN, PhD, was responsible for article revision. Jeffrey R. Masuda, PhD, performed data collection, analysis, and intervention implementation in the Manitoba site. Lisa Bourque Bearskin, RN, MN, PhD candidate, was responsible for collaborating with Aboriginal organizations. Sharon Anderson, MEd, MSc, PhD, was responsible for data collection and analysis, as well as draft report preparation for the funder. Roxanne Blood, BA, was responsible for intervention implementation.

\section{Acknowledgements}

The following team members made this project possible: Mara Fridell, site coordinator (Manitoba); Carey Sinclair, research assistant (Manitoba); Hazel McKennitt, chair, community advisory committee in Alberta; Rob Watson, Nova Scotia site coordinator.

We are grateful to the parents and caregivers who participated in interviews and in support intervention activities. The team appreciates that you shared your time, experience, and 
Supporting Parents of Aboriginal Children with Asthma: Preferences and Pilot Interventions - Miriam Stewart, Heather Castleden, Malcolm King, Nicole Letourneau, Jeffrey R. Masuda, Lisa Bourque Bearskin, Sharon Anderson, Roxanne Blood

insights. Funding provided by AllerGen NCE for Alberta, Manitoba, and Nova Scotia sites; CIHR for Alberta site.

\section{Introduction}

Asthma and allergies continue to pose major health challenges in Canada (Statistics Canada, 2013), particularly among Aboriginal children, imposing negative impacts on physical health, psychosocial well-being, and quality of life (First Nations Information Governance Centre [FNIGC] , 2007; Chang, Beach, \& Senthilselvan, 2012) and high rates of hospitalization and emergency room visits (Rosychuk et al., 2010; To, Dell, Tassoudji, \& Wang, 2009). Although asthma and allergies have been reported to be the most common chronic conditions affecting Aboriginal children and adolescents in Canada (King, Zayas, \& Martial, 2004; Kovesi, 2012), some recent data suggest that the prevalence is similar (12\%) to other Canadian children (Crighton, Wilson, \& Senécal, 2010; MacMillan et al., 2010). However, asthma may be underdiagnosed among Aboriginal people in isolated or remote areas (Gessner \& Neeno, 2005). Low levels of asthma control and more emergency room visits may also be linked to reduced access to asthma specialists for rural and/or isolated populations (Sin, Wells, Svenson, \& Man, 2002).

Canadian studies (McIvor, Boulet, FitzGerald, Zimmerman \& Chapman, 2007; Public Health Agency of Canada, 2008) reveal high health burdens related to asthma and relevant risk factors such as smoking. Hospitalization rates linked to asthma and bronchitis among Aboriginal children increased $200 \%$ since the 1980 s, compared with a $50 \%$ increase for non-Aboriginal children (FNIGC, 2007; Boffa, King, McMullin, \& Long, 2011). Thirteen percent of First Nations children under 19 have asthma, and associated treatment levels are low (Crighton et al., 2010; First Nations Information Governance Centre [FNIGC], 2011). Despite the higher rates of respiratory illness and associated health care utilization among Aboriginal children, factors underpinning inequitable health outcomes require elucidation (Crighton et al., 2010; Rosychuk et al., 2010).

Risk factors for Aboriginal people with asthma include higher exposure to overcrowded housing and air pollution, higher smoking rates among First Nations youth (FNIGC, 2007), and lower use of specialist services suggesting access barriers (Sin, Svenson, Cowie, \& Man, 2003). In Alberta, parents of Aboriginal children with asthma describe time-consuming caregiving demands (Sin et al., 2002), mood and anxiety disorders, and depression linked with asthmarelated hospitalizations of their children (Lee, Parker, DuBose, Gwinn, \& Logan, 2006).

Social support is a determinant of health, a health promotion mechanism, and a protective factor in resilience for Aboriginal Canadians (Richmond, Ross, \& Bernier, 2007; Richmond, Ross, \& Egeland, 2007). Significant gaps in social support and social isolation for children with asthma and allergies and their parents have been reported in previous research (Cicutto et al., 2005; Kapoor et al., 2004; McGhan et al., 2003; Tsuyuki, Sin, \& Sharpe, 2005). Families of nonAboriginal children with chronic conditions, including asthma, report a desire for more information support (Farmer, Marien, Clark, Sherman, \& Selva, 2004; Kieckhefer \& Ratcliffe, 2000). Income challenges and changing help patterns in Aboriginal communities negatively affect support reciprocity (Richmond, 2007). Aboriginal parents could benefit from support to help manage asthma and allergies (FNIGC, 2007), but their support intervention needs and preferences have not been studied. Despite reported needs for support from peers in similar situations for children and adolescents with asthma (Bruzzese et al., 2004; Kyngas, 2004) and their parents (Kieckhefer \& Ratcliffe, 2000), and the importance of peers for Aboriginal children 
Supporting Parents of Aboriginal Children with Asthma: Preferences and Pilot Interventions - Miriam Stewart, Heather Castleden, Malcolm King, Nicole Letourneau, Jeffrey R. Masuda, Lisa Bourque Bearskin, Sharon Anderson, Roxanne Blood

and adults (Valentine, Dawar, \& Wardman, 2003), support programs engaging peers have not been tested. Moreover, interventions that address the support needs identified by Aboriginal children with asthma and allergies and their parents are exceedingly rare (Stewart et al., 2013; Watson, Castleden, Masuda, King, \& Stewart, 2012).

The research reported is part of a multisite study examining support intervention preferences of Aboriginal children and youth with asthma and their parents/caregivers and developing pertinent interventions. The focus of this paper is the design and testing of support interventions, based on parents' assessed support needs and preferences. Accordingly, the objectives of this study were the following:

1. Assess the support resources, support needs, support-seeking strategies, and support preferences of parents of Aboriginal children with asthma and allergies.

2. Develop and implement an accessible and appropriate support intervention for these Aboriginal parents that overcomes geographic, physical, cultural, and temporal barriers and is based on their articulated preferences.

3. Evaluate health-related impacts of pilot support interventions deemed culturally appropriate by Aboriginal stakeholders.

Figure 1 depicts the progression from assessment of support needs and preferences to

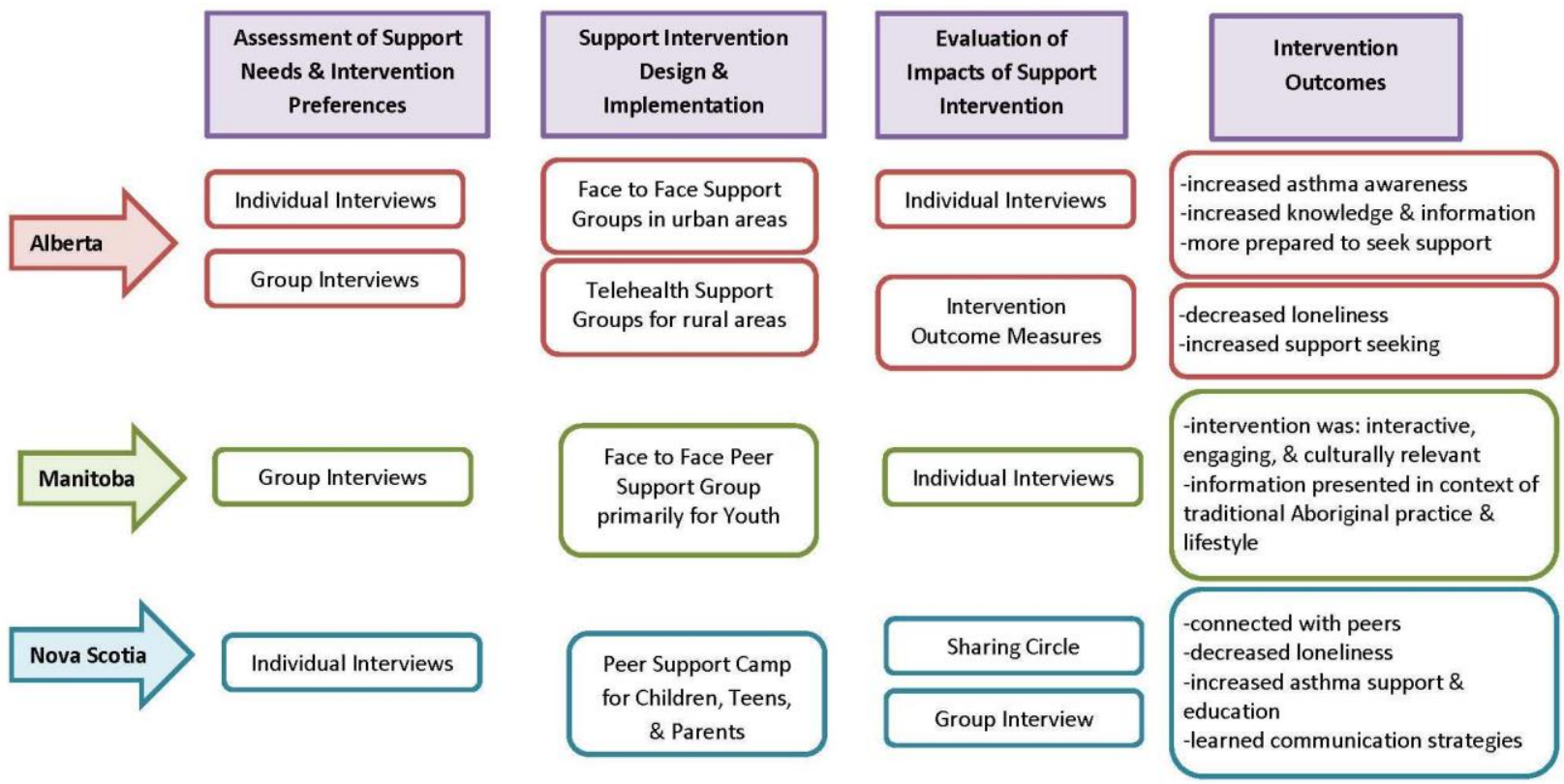

intervention design, implementation evaluation, and outcomes across the three study sites (Canadian provinces).

Figure 1.

Project progression

\section{Methods}

The study was conducted by an interdisciplinary research team encompassing Aboriginal researchers and knowledge users, and employed a multimethod participatory research design (Bergold \& Thomas, 2012; Tashakkori \& Teddlie, 2003), with guidance from Aboriginal community advisory committees. Consistent with principles of participatory research (Ahmed, Beck, Maurana, \& Newton, 2004; Bergold \& Thomas, 2012; Boffa et al., 2011), parents of 
Supporting Parents of Aboriginal Children with Asthma: Preferences and Pilot Interventions - Miriam Stewart, Heather Castleden, Malcolm King, Nicole Letourneau, Jeffrey R. Masuda, Lisa Bourque Bearskin, Sharon Anderson, Roxanne Blood

Aboriginal children and adolescents with asthma specified their preferred type, format, and substantive content of support interventions; helped select specific interventions; and suggested changes for future interventions. The Aboriginal community advisory committees in each of the three study sites (Alberta, Manitoba, Nova Scotia) guided selection, screening, and training of project staff; development and amendment of interview guides and measures; identification of culturally appropriate recruitment strategies; design of the intervention; identification of optimum intervention outcomes; and knowledge translation strategies.

Mixed methods (i.e., qualitative and quantitative) were used to corroborate, elaborate, and illuminate, thereby enhancing validity, transferability, and confidence (Creswell, 2013; Tashakkori \& Teddlie, 2003). Qualitative methods were employed to promote understanding of sensitive issues, meanings, perceptions, beliefs, values, and behaviours regarding support needs, support intervention preferences, anticipated outcomes, and appropriate intervention(s) and outcomes (Ahmed et al., 2004; Schulze, 2003). Qualitative data on intervention processes and factors influencing the intervention gave voice to the experiences of participants and helped elucidate the "black box" (who, what, where, when, why, how) of the psychosocial interventions (Stewart, Letourneau, \& Kushner, 2010). Quantitative methods elicited data relevant to testing outcomes through structured measures administered prior to and following the intervention. Quantitative measurements helped extend and refine qualitative data (Schulze, 2003) and may enable potential relevance (Creswell, 2013; Schulze, 2003) for other Aboriginal parents of children with asthma.

\section{Community Advisory Committees}

\section{Relationships}

Three community advisory committees were created to include representatives of the First Nations and Inuit Health federal government branch, Aboriginal health service organizations, and First Nations and Métis communities.

\section{Alberta.}

A community advisory committee comprising 10 Aboriginal community leaders provided guidance on the development, implementation, and evaluation of the study. To protect the rights of Aboriginal children, adolescents, and their parents, this committee reviewed the process of informed consent (e.g., information letters, consent forms) for cultural and linguistic appropriateness. The study was approved by Aboriginal community leaders, participating agencies and organizations, and the university ethics committee. Urban and rural communities were selected as study sites in consultation with the community advisory committee.

\section{Manitoba.}

Research undertaken with First Nations people in Manitoba requires formal approval from the Health Information and Research Governance Committee, an oversight body comprising researchers, elders, staff, and representatives of the Assembly of Manitoba Chiefs. The research team formalized a research partnership with Dakota Tipi First Nation, a reserve located south of the small town of Portage La Prairie. The elders determined that the study, as a community-based participatory project with previously secured support of the Assembly of Manitoba Chiefs and its research ethics supervisors, was consistent with the community's health goals. 
Supporting Parents of Aboriginal Children with Asthma: Preferences and Pilot Interventions - Miriam Stewart, Heather Castleden, Malcolm King, Nicole Letourneau, Jeffrey R. Masuda, Lisa Bourque Bearskin, Sharon Anderson, Roxanne Blood

\section{Nova Scotia.}

Relationships were developed with five Mi'kmaq communities (Eskasoni, Waycobah, Wagmatcook, Potlotek, and Membertou) in Unama'ki (Cape Breton), Nova Scotia, through each community's health director. Once this relationship was established, a local advisory committee (consisting of community health nurses and community health representatives from each community) was appointed by the health directors to guide the research in these communities. Ethics approval was secured from Dalhousie University's Health Sciences Research Ethics Board, as well as from the Mi'kmaw Ethics Watch, an independent process to ensure that research involving Mi'kmaq people is culturally appropriate and safeguards Indigenous knowledge (Mi'kmaw Ethics Watch, 1999).

The following sections describe the specific methods and results for each objective. The process and results organized by provincial site are summarized in Appendices A through C.

\section{Assessment of Support Needs and Intervention Preferences (Objective 1)}

\section{Participants and Procedures}

Seventy-seven parents of Aboriginal children with asthma and allergies participated in the assessment interviews to express preferences regarding support interventions (Alberta, $n=54$; Manitoba, $n=9$; Nova Scotia, $n=17$ ).

\section{Alberta.}

Parents from three Métis communities (Buffalo Lake, Kikano, Elizabeth) and nine First Nations communities (Blood Tribe, Cold Lake First Nations, Enoch Cree Nation, Fort McKay, Kehewin, Whitefish Lake First Nation, Siksika Nation, Samson Cree Nation, Tsuu T'ina Nation) in Alberta participated in these interviews. Individual in-depth interviews with parents were conducted in person $(n=51)$ by trained Aboriginal community-based interviewers. Data saturation (i.e., no new themes in the qualitative interview data; Creswell, 2013) helped determine when recruitment of participants was completed.

A semi-structured individual interview guide was used to elicit parents' perceptions of (a) their caregiving demands and challenges requiring support; (b) their coping strategies, including support seeking; (c) their support needs and support resources; (d) programs serving Aboriginal children/adolescents with asthma and their parents; (e) gaps in supports and services; (f) preferences for culturally appropriate support interventions for children and parents; and (g) culturally appropriate intervention outcomes. Two in-depth group interviews with parents/ guardians ( $n=25$ ) were subsequently conducted in Alberta (one rural, one urban) to verify and clarify specific features of recommended support interventions.

The community advisory committee (nine leaders/elders from First Nations and Métis communities and three Aboriginal health professionals) met in a one-day retreat to (a) discuss results of these individual and group interviews and (b) provide advice on design of support interventions for urban and rural settings in Alberta. The research team and the community advisory committee leaders, an Aboriginal elder, and Aboriginal research assistants met to discuss the design, development, and evaluation of support interventions based on parents' needs and preferences revealed through interviews.

\section{Manitoba.}

Nine caregivers, including three parents, five guardians/relatives, and a professional caregiver participated in a group interview. Seven caregivers were Dakota, one was Métis, and 
Supporting Parents of Aboriginal Children with Asthma: Preferences and Pilot Interventions - Miriam Stewart, Heather Castleden, Malcolm King, Nicole Letourneau, Jeffrey R. Masuda, Lisa Bourque Bearskin, Sharon Anderson, Roxanne Blood

one was a Euro-Canadian parent of an Aboriginal child. During group interviews, participants received a synopsis of the results from individual interviews and were asked if the interpretations were accurate and appropriate in their view.

\section{Nova Scotia.}

With guidance from the advisory committee, six Mi'kmaq community researchers were trained in participant recruitment and qualitative data collection techniques. Mi'kmaq families (including 17 parents) were recruited from across five communities. The community researchers conducted semistructured individual interviews with parents to identify their asthma-related support needs and intervention preferences. Interviews were conducted in English with occasional, spontaneous use of Mi'kmaq if participants preferred and the community researcher knew the language.

\section{Results}

\section{Alberta.}

Parents perceived that they lacked support to manage their children's asthma and allergies. Some parents indicated they had insufficient information regarding health implications of asthma, prescribed and traditional medication use, and allergen avoidance. They were concerned about mold in their homes and environmental risks (e.g., dust, smoking, ground fires). Parents wanted support to understand and manage asthma; information on use of prescribed, over-the-counter, and traditional medications; advice regarding communication strategies with health professionals; and insights from other Aboriginal parents on management of their children's health condition. Some parents thought people in their Aboriginal communities were unaware how many Aboriginal children were affected by asthma and other respiratory health conditions. They wanted advice from health professionals, along with face-to-face support from both Aboriginal peers and professionals. Parents contended that they needed culturally appropriate support, education, community awareness, and child care during support intervention sessions. Parents confirmed that Telehealth - oneHealth was an appropriate vehicle for delivering support and selected relevant topics for discussion in peer support groups.

\section{Manitoba.}

Dusty roads, insufficient federal support of housing, overcrowded multigenerational housing, nearby air-polluting industry, poverty, and concomitant risky health behaviours were identified as conditions contributing to poor respiratory health as well as to major support deficits and support needs. Intervention preferences focused primarily on children's and adolescents' needs, including an after-school group.

\section{Nova Scotia.}

Virtually all parents were aware of their child's specific asthma "triggers" (e.g., household mold, smoking, animal dander, exercise, seasonal change, extreme cold or humidity) and had developed some prevention strategies for avoiding triggers. They relied on lived experience and medical advice when managing their child's asthma, and reported insufficient community-level asthma support. Geographic distance was identified as a major barrier to accessing supports outside their communities. Moreover, support resources external to their communities were available only in English, whereas Mi'kmaq was the preferred language for many parents. Parents noted reliance on other family members for psychosocial support needs, and on health professionals for information regarding physiological aspects of asthma. Parents desired increased information and educational resources to help manage their child's asthma. 
Supporting Parents of Aboriginal Children with Asthma: Preferences and Pilot Interventions - Miriam Stewart, Heather Castleden, Malcolm King, Nicole Letourneau, Jeffrey R. Masuda, Lisa Bourque Bearskin, Sharon Anderson, Roxanne Blood

Recommended support interventions included education, support groups, and information provided in Mi'kmaq language. Parents suggested culturally relevant, school-based asthma support and awareness training.

\section{Support Intervention Development and Implementation (Objective 2)}

Forty parents/caregivers of Aboriginal children with asthma and allergies participated in the pilot support interventions (Alberta, $n=20$; Manitoba, $n=3$; Nova Scotia, $n=17$ ). All interventions were designed to provide support and education for these parents. Specific interventions in each site were determined by preferences expressed in assessment interviews regarding intervention mode (e.g., face-to-face, telephone); supporters/helpers (e.g., peers, professionals); timing, frequency, and duration of support sessions; and discussion topics. All support programs were facilitated by trained Aboriginal peer mentors, health professionals, and/or Aboriginal elders. To accommodate preferences of parents in different communities and distance to rural Aboriginal communities, diverse pilot support interventions were designed, implemented, and pilot tested in the three study sites. To enhance accessibility of these interventions for parents of Aboriginal children regardless of socioeconomic status and geographic location, transportation and child care were provided when needed. Similar postintervention interview guides were used across all three sites.

\section{Participants and Procedures}

\section{Alberta.}

Twenty parents/caregivers from one rural reserve $(n=8)$ and an urban centre $(n=12)$ 15 First Nation, 4 Métis, and 1 Caucasian-participated in the support interventions in Alberta. Participants comprised 15 parents, three grandparents, and two guardians caring for First Nations or Métis children. Parents in the assessment interviews recommended pilot face-to-face support programs in one urban and one rural community, and suggested Telehealth as a delivery mechanism for rural parents. Consistent with these preferences, face-to-face support group interventions, supplemented by Telehealth, were implemented and tested.

Eight support group sessions were delivered by professionals through Telehealth to rural Aboriginal parents. Following each session, an Aboriginal peer facilitator and Aboriginal health professional provided face-to-face support in the rural First Nations health centre. To accommodate distance, oneHealth (the Telehealth portal sponsored by First Nations and Inuit Health) was used to link rural and remote First Nations communities to health professionals with expertise relevant to asthma and allergies. Parents met at the health centre to interact with health experts and peers on Telehealth - oneHealth. Topics included asthma management, use of asthma medications, communicating with health professionals, keeping homes allergen and mold free, avoiding asthma triggers, culturally relevant and safe use of traditional medicine, tobacco, etc. After each formal Telehealth session ended, parents at the health centre discussed with a trained Aboriginal peer mentor and health professional what they learned and how that applied to management of their child's condition. As the sessions at the health centre were open to the community, approximately 20 extra people attend the in-person group sessions, in addition to the 8 participants who attended most sessions and completed the pre and postintervention interviews and measures. As the sessions were available to all First Nations and Métis health centres through the oneHealth portal, an average of 30 Aboriginal people at 15 rural health centres also participated in each session. These sessions continue to be available on the oneHealth Internet site. 
Supporting Parents of Aboriginal Children with Asthma: Preferences and Pilot Interventions - Miriam Stewart, Heather Castleden, Malcolm King, Nicole Letourneau, Jeffrey R. Masuda, Lisa Bourque Bearskin, Sharon Anderson, Roxanne Blood

Eight face-to-face support group sessions were delivered by a trained Aboriginal peer mentor and a health professional weekly at an inner city school with an infused Aboriginal curriculum. These urban parents discussed topics similar to those requested by rural parents, but also wanted information on urban services and supports. Both support group sessions lasted two to three hours.

All 20 parents were interviewed individually prior to and following these support interventions. A 10-item semistructured interview guide elicited qualitative data regarding intervention processes, perceived intervention impacts, and recommended changes. Three standardized quantitative measures-UCLA Loneliness Scale (Russell, 1996), Personal Resource Questionnaire (Weinert, 2003), and Proactive Coping Inventory (Greenglass, Schwarzer, \& Taubert, 1999) — were administered to parents. These were deemed culturally appropriate by the Aboriginal advisors and had good psychometric properties. These quantitative pretest and posttest measures were administered only in the Alberta site.

\section{Manitoba.}

Although the urban Manitoba intervention was designed primarily for adolescents with asthma and allergies, three parents from the Dakota Tipi tribe (2 mothers, 1 father) attended faceto-face support group sessions and participated in postintervention qualitative interviews.

\section{Nova Scotia.}

The same $17 \mathrm{Mi}$ 'kmaq rural parents who participated in assessment interviews attended, with their children, a 2-day asthma camp that combined needs assessment with support intervention. The camp intervention included Aboriginal ceremonies (smudging, prayer); cultural activities (drum-making, drumming, singing, dancing); entertainment (games, art, relay races, movie night); social support (informal networking opportunities); and education (asthma awareness training, guest speakers with expertise in asthma support). Intervention activities had spontaneous bursts of Mi'kmaq language use but the activities were not formally conducted in the language. One sharing circle and one focus group were held with the parents/caregivers and were facilitated by community researchers. The sharing circle and focus group were digitally recorded and transcribed to ensure accuracy. The research team observed participants, recorded field notes, and held two debriefing sessions during the gathering. All data were translated and transcribed in English.

\section{Evaluation of Impacts of Pilot Support Intervention (Objective 3)}

Data collection strategies included the following: standardized measures, individual interviews, a sharing circle, and a group interview.

\section{Results}

\section{Alberta.}

Based on results from the Personal Resource Questionnaire, urban Aboriginal parents reported significantly more social support resources than rural participants. Although the social support (Personal Resource) scores increased for both rural and urban participants following the support interventions, increases were not statistically significant. Loneliness mean scores were significantly lower at posttest, following the support intervention, than at pretest. Support seeking (as measured by the Proactive Coping Inventory) increased at posttest; however, this increase was not statistically significant. 
Supporting Parents of Aboriginal Children with Asthma: Preferences and Pilot Interventions - Miriam Stewart, Heather Castleden, Malcolm King, Nicole Letourneau, Jeffrey R. Masuda, Lisa Bourque Bearskin, Sharon Anderson, Roxanne Blood

In the posttest qualitative interviews, which extended and refined the data elicited by the quantitative measures, parents reported that they were more prepared to seek support following the interventions, but that support resources were only minimally available in their communities. They believed the support interventions had raised awareness of asthma in their community. Parents described the increased capacity of staff members at health centres to be community champions for asthma support following the support intervention.

My biggest wish is . . . if every health centre in [our region] would take one person and really seriously train them on this topic. So then they could pass on the information to the parents. Because a lot of the parents don't have the proper information or they are not sure how to give the medication. That's all I wish for. (Aboriginal mother)

Rural parents appreciated meeting on Telehealth, although oneHealth was available only from 9 a.m. to 5 p.m. Urban parents valued information regarding asthma and allergies received during the intervention. In postintervention interviews, urban parents said that after their positive experience with peer support from the support group interventions, they wanted similar support resources relevant to other challenges in their lives (e.g., siblings of child with asthma):

I learnt something new in each [support group] session; I did not know everything. I learnt bits and pieces where I had a better understanding of asthma. But for mold basically the reason why we had mold is because it [our home] wasn't properly built and then we had to move out of the house because it was improperly built. (Parent)

That's a big thing, because most times you go to the drugstore, you take your prescription and it's just given to you and now we have information there [in support group] on how to use it [the medication] properly. (Father)

One mother informed support group members that she was frustrated trying to find the right medication for her son:

That's where a lot of them say that [my son] could have been on the same medication for years and didn't know if that's not helping him any. They can go back and get them assessed for something else that going to eventually work for them. They have to go through so many medications for one that's going to actually work for him.

Parents of Aboriginal children with asthma wanted accessible delivery of health information to their community:

Actually that's really what I like [about] it [Telehealth sessions], then you don't have to go to the city to talk to the specialist, right? They brought the specialist to us, well they had it here. (Mother)

These parents emphasized how the support intervention helped them cope with their children's asthma:

Actually using the information on clients that I wasn't able to with my son, like I, I was aware working with my own son, but working with others now I'm actually going out 
Supporting Parents of Aboriginal Children with Asthma: Preferences and Pilot Interventions - Miriam Stewart, Heather Castleden, Malcolm King, Nicole Letourneau, Jeffrey R. Masuda, Lisa Bourque Bearskin, Sharon Anderson, Roxanne Blood

showing them how to use their inhalers with the spacer properly or doing the referral for them or giving their information to [health professional mentor] so they can utilize her. (Mother)

Participating parents and family caregivers noted other positive contributions of the support program:

That helps because ... some people are terrified and they don't want to talk about it in a public setting when you're there and then you kind of say, "Hey, it's okay." Then you kind of direct them to who would know that answer that they're looking for. (Mother)

Participants reported that they learned from the inquiries of other parents in the support groups:

People ask questions that you don't even think about asking and then they'll say, "Oh yeah that, you know, that's another thing that I should have asked" and your questions are being answered, so yeah. (Mother)

\section{Manitoba.}

Parents perceived that the after-school support intervention for Aboriginal youth and parents/caregivers was interactive, engaging, culturally relevant, and community led. As one community elder who was the support program facilitator stated:

[At first] I assumed it was going to be more of an information session, based on the lungs, you know, how the lungs operate and, you know, the deterrents, the pros and the cons, you know, but ultimately it became a lot more than that ... that was the good thing about it because ... we had the dance, we had the games, we had our culture, all those components, you know, condensed into one.

The delivery of asthma information within the context of traditional practices and lifestyles was appreciated by community members. Parents also appreciated the positive "demystification" of research by the support intervention activities, which stimulated their interest in community-based research and in life pathways beyond the reserve.

\section{Nova Scotia.}

Virtually all family caregivers commented on the value of the asthma camp intervention for connecting with their peers, specifically other Mi'kmaq parents dealing with asthma-related issues. According to these parents, the camp reduced their loneliness, improved asthma support and education, enabled social learning, enhanced friendships and family communication, and taught strategies for communicating with other community members. Participants also suggested that future community-based health interventions be undertaken in the language used by the community. Caregivers expressed a strong desire for ongoing support groups. One mother explained: "We need support groups ... I really don't have anyone else to go [to] other than my doctor."

\section{Limitations}

This pilot study had small sample sizes, particularly in some sites. Moreover, data collection techniques across sites were similar but not identical. 
Supporting Parents of Aboriginal Children with Asthma: Preferences and Pilot Interventions - Miriam Stewart, Heather Castleden, Malcolm King, Nicole Letourneau, Jeffrey R. Masuda, Lisa Bourque Bearskin, Sharon Anderson, Roxanne Blood

\section{Discussion and Conclusion}

Across the three sites, parents reported challenges with sudden and severe asthma attacks, knowledge gaps, poverty, blame imposed on parents for their child's illness, underdiagnosis, uncoordinated health care, disrespectful treatment, environmental problems, and lack of culturally appropriate support. Diverse support intervention strategies were designed to address these challenges and were well received by parents of Aboriginal children, who described decreased support and education needs following the intervention across urban and rural sites, many of which were low-income. These perceived impacts are timely given recent government reports that social support gaps, coupled with high rates of poverty, create significant disparities in life chances between Aboriginal and non-Aboriginal children (Canadian Council of Child and Youth Advocates, 2011; Standing Senate Committee on Human Rights, 2007). Health problems related to asthma and allergies among Aboriginal children should be considered in the context of salient influences including social relationships, educational and community institutions, environmental conditions, government policies, and culture (Crighton et al., 2010; Nettleton, Napolitano, \& Stephens, 2007).

Parents could benefit from support and education in assisting their Aboriginal children to manage asthma. It is crucial for parents to understand what asthma is, what the symptoms are, what the signs of a severe asthma attack are, how to manage aggravations and when to pursue medical care, and how to avoid triggers (Kovesi, Giles, \& Pasterkamp, 2012). Peer support and community education can enhance respiratory health, indoor and outdoor environments, and health behaviours in Aboriginal communities (Bhattacharyya et al., 2011; Richmond, 2007). There is abundant evidence of the detrimental impacts of asthma and allergies on parents, including loneliness, isolation, and support deficiencies (Bjorksten, 2000; Couriel, 2003). Indeed, social exclusion and social isolation have been associated with poor health outcomes and are intertwined with other social determinants of health, such as ethnicity, income, and social support (Marmot, 2007; Raphael, 2007). However, no previous studies had designed and tested support interventions that address the unique support deficiencies, needs, and preferences of parents of Aboriginal children with asthma in Canada. As there is little evidence available on effectiveness of different modes of support interventions for Aboriginal parents, and as participatory principles are paramount in research engaging Aboriginal people (Tri-Council, 2010), this study asked Aboriginal parents and Aboriginal service providers to select preferred interventions for specific groups (rural/urban), and pilot tested the unique intervention(s) selected by Aboriginal people in each site. These accessible support interventions fostered resilience and coping of Aboriginal parents in both urban and rural sites, and transcended physical and geographic barriers.

Similar peer support interventions can improve relevance and uptake of health programs through support provision informed by needs and wishes of Aboriginal parents; increase the efficacy of health interventions by supplementing professional knowledge with credible experiential knowledge of peers; enhance capacity of Aboriginal parents to manage asthma and support others; enhance accessibility of interventions for Aboriginal parents that address cultural and geographic inequities; and inform development of policies promoting collaboration of health-related sectors. As this pilot research illustrates, community-based participatory interventions developed to meet the specific needs and wishes of parents in unique Aboriginal communities can be accessible and acceptable. This "different strokes for different folks" strategy reflects participatory principles, and seems to be more acceptable and accessible than a 
Supporting Parents of Aboriginal Children with Asthma: Preferences and Pilot Interventions - Miriam Stewart, Heather Castleden, Malcolm King, Nicole Letourneau, Jeffrey R. Masuda, Lisa Bourque Bearskin, Sharon Anderson, Roxanne Blood

generic "one size fits all" approach to interventions for vulnerable parents and caregivers of Aboriginal children with this chronic health condition.

\section{References}

Ahmed, S. M., Beck, B., Maurana, C. A., \& Newton, G. (2004). Overcoming barriers to effective community-based participatory research in US medical schools. Education for Health, 17(2), 141-151.

Bergold, J., \& Thomas, S. (2012). Participatory research methods: A methodological approach in motion. Historical Social Research, 37(4), 191-222.

Bhattacharyya, O. K., Rasooly, I. R., Naqshbandi, M., Estey, E. A., Esler, J., Toth, E., ... Harris, S. B. (2011). Challenges to the provision of diabetes care in First Nations communities: Results from a national survey of healthcare providers in Canada. BMC Health Services Research, 11, 283. doi:10.1186/1472-6963-11-283

Bjorksten, B. (2000). Unmet needs in the treatment of asthmatic children and adolescents. Clinical \& Experimental Allergy, 30, 73-76. doi:10.1046/j.1365-2222.2000.00103.x

Boffa, J., King, M., McMullin, K., \& Long, R. (2011). A process for the inclusion of Aboriginal people in health research: Lessons from the Determinants of TB Transmission Project. Social Science and Medicine, 72(5), 733-738. doi:10.1016/j.socscimed.2010.10.033

Bruzzese, J., Bonner, S., Vincent, E. J., Sheares, B. J., Mellins, R. B., Levison, M. J, ... Evans, J. (2004). Asthma education: The adolescent experience. Patient Education and Counseling, 55, 396-406. doi:10.1016/j.pec.2003.04.009

Canadian Council of Child \& Youth Advocates. (2011). Aboriginal children: Canada must do better: Today and tomorrow. Retrieved from http://provincialadvocate.on.ca/documents/en/CCCYA_UN_Report.pdf

Chang, H., Beach, J., \& Senthilselvan, A. (2012). Prevalence of and risk factors for asthma in off-reserve Aboriginal children and adults in Canada. Canadian Respiratory Journal, 19(6), e68-e74. doi:10.1155/2012/753040

Cicutto, L., Murphy, S., Coutts, D., O’Rourke, J., Lang, G., Chapman, C., \& Coates, P. (2005). Breaking the access barrier: Evaluating an asthma center's efforts to provide education to children with asthma in schools. Chest, 128(4), 1928-1935.

Couriel, J. (2003). Asthma in adolescence. Paediatric Respiratory Reviews, 4, 47-54. doi:10.1016/S1526-0542(02)00309-3

Creswell, J. W. (2013). Qualitative inquiry and research design: Choosing among five approaches (3rd ed.). Thousand Oaks, CA: Sage. 
Supporting Parents of Aboriginal Children with Asthma: Preferences and Pilot Interventions - Miriam Stewart, Heather Castleden, Malcolm King, Nicole Letourneau, Jeffrey R. Masuda, Lisa Bourque Bearskin, Sharon Anderson, Roxanne Blood

Crighton, E. J., Wilson, K., \& Senécal, S. (2010). The relationship between socioeconomic and geographic factors and asthma among Canada's Aboriginal populations: An analysis of the 2001 Aboriginal People's Survey. International Journal of Circumpolar Health, 69(2), 138-150. doi:10.3402/ijch.v69i2.17435

Farmer, J. E., Marien, W. E., Clark, M. J., Sherman, A., \& Selva, T. J. (2004). Primary care supports for children with chronic health conditions: Identifying and predicting unmet family needs. Journal of Pediatric Psychology, 29(5), 355-367. doi:10.1093/jpepsy/jsh039

First Nations Information Governance Centre (FNIGC). (2007). First Nations Regional Longitudinal Health Survey: Our voice, our survey, our reality. Selected results from RHS Phase 1 (2002/03). Ottawa, ON: Author.

First Nations Information Governance Centre (FNIGC). (2011). First Nations Regional Longitudinal Health Survey. RHS Phase 2 (2008/10): Preliminary results. Retrieved from http://fnigc.ca/sites/default/files/RHSPreliminaryReport.pdf

Gessner, B. D., \& Neeno, T. (2005). Trends in asthma prevalence, hospitalization risk, and inhaled corticosteroid use among Alaska Native and non-Native Medicaid recipients younger than 20 years. Annals of Allergy, Asthma \& Immunology, 94, 372-379. doi:10.1016/s1081-1206(10)60990-8

Greenglass, E. R., Schwarzer, R., \& Taubert, S. (1999). The Proactive Coping Inventory (PCI): A multidimensional research instrument. York University, Toronto, ON. Retrieved from http://userpage.fu-berlin.de/ health/greenpci.htm

Kapoor, S., Roberts, G., Bynoe, Y., Gaughan, M., Habibi, P., \& Lack, G. (2004). Influence of a multidisciplinary paediatric allergy clinic on parental knowledge and rate of subsequent allergic reactions. Allergy, 59, 185-191. doi:10.1046/j.1398-9995.2003.00365.x

Kieckhefer, G. M., \& Ratcliffe, M. (2000). What parents of children with asthma tell us. Journal of Pediatric Health Care, 1, 122-126.

King, M., Zayas, G., \& Martial, R. (2004). Cardiovascular and respiratory health risks in Canada's Aboriginal population. Pimatisiwin, 2, 75-95.

Kovesi, T. (2012). Respiratory disease in Canadian First Nations and Inuit children. Paediatrics \& Child Health, 17(7), 376-380.

Kovesi, T., Giles, B. L., \& Pasterkamp, H. (2012). Long-term management of asthma in First Nations and Inuit children: A knowledge translation tool based on Canadian paediatric asthma guidelines, intended for use by front-line health care professionals working in isolated communities. Paediatrics \& Child Health, 17(7), e46-e64. 
Supporting Parents of Aboriginal Children with Asthma: Preferences and Pilot Interventions - Miriam Stewart, Heather Castleden, Malcolm King, Nicole Letourneau, Jeffrey R. Masuda, Lisa Bourque Bearskin, Sharon Anderson, Roxanne Blood

Kyngas, H. A. (2004). Support network of adolescents with chronic disease: Adolescents' perspective. Nursing and Health Sciences, 6, 287-293.

doi:10.1111/j.1442-2018.2004.00207.x

Lee, E. J., Parker, V., DuBose, L., Gwinn, J., \& Logan, B. N. (2006). Demands and resources: Parents of school-age children with asthma. Journal of Pediatric Nursing, 21, 425-433. doi:10.1016/j.pedn.2006.05.003

Marmot, M. (2007). Achieving health equity: From root causes to fair outcomes. Lancet, 370, 1153-1163. doi:10.1016/s0140-6736(07)61385-3

McGhan, S. L., Wong, E., Jhangri, G. S., Well, H. M., Michaelchuck, D. R., Boechler, V. L. ... Hessel, P. A. (2003). Evaluation of an education program for elementary school children with asthma. Journal of Asthma, 40, 523-533. doi:10.1081/jas-120018785

McIvor, R. A., Boulet, L. P., FitzGerald, J. M., Zimmerman, S., \& Chapman, K. R. (2007). Asthma control in Canada: No improvement since we last looked in 1999. Canadian Family Physician, 53, 673-677.

MacMillan, H. L., Jamieson, E., Walsh, C., Boyle, M., Crawford, A., \& MacMillan, A. (2010). The health of Canada's Aboriginal children: Results from the First Nations and Inuit Regional Health Survey. International Journal of Circumpolar Health, 69(2), 158-167. doi:10.3402/ijch.v69i2.17439

Mi'kmaw Ethics Watch. (1999). Research principles and protocols. Sydney, NS: Cape Breton University.

Nettleton, C., Napolitano, D. A., \& Stephens, C. (2007). An overview of current knowledge of the social determinants of Indigenous health. Commission on Social Determinants of Health, World Health Organization. Retrieved from http://som.flinders.edu.au/FUSA/SACHRU/Symposium/Social\%20Determinants\%20of\%2 OIndigenous $\% 20$ Health.pdf

Public Health Agency of Canada. (2008). The Chief Public Health Officer's report on the state of public health in Canada. Retrieved from http://www.phac-aspc.gc.ca/cphorsphcrespcacsp/2008/fr-rc/index-eng.php

Raphael, D. (2007). Poverty and policy in Canada: Implications for health and quality of life. Toronto, ON: Canadian Scholars' Press.

Richmond, C. A. M. (2007). Narratives of social support and health in Aboriginal communities. Canadian Journal of Public Health, 98(4), 347-351. 
Supporting Parents of Aboriginal Children with Asthma: Preferences and Pilot Interventions - Miriam Stewart, Heather Castleden, Malcolm King, Nicole Letourneau, Jeffrey R. Masuda, Lisa Bourque Bearskin, Sharon Anderson, Roxanne Blood

Richmond, C., Ross, N., \& Bernier, J. (2007). Exploring Indigenous concepts of health: The dimensions of Métis and Inuit health. In J. White, D. Beavon, S. Wingert, \& P. Maxim (Eds.), Aboriginal policy research: Directions and outcomes (Vol. 4, pp. 3-13). Toronto, ON: Thompson Educational Publishing.

Richmond, C. A., Ross, N. A., \& Egeland, G. M. (2007). Social support and thriving health: A new approach to understanding the health of Indigenous Canadians. American Journal of Public Health, 97, 1827-1833. doi:10.2105/ajph.2006.096917

Rosychuk, R. J., Voaklander, D. C., Klassen, T. P., Senthilselvan, A., Marie, T. J., \& Rowe, B. H. (2010). Asthma presentations by children to emergency departments in a Canadian province: A population-based study. Pediatric Pulmonology, 45(10), 985-992. doi:10.1002/ppul.21281

Russell, D. W. (1996). UCLA Loneliness Scale (version 3): Reliability, validity, and factor structure. Journal of Personality Assessment, 66(1), 20-40. doi:10.1207/s15327752jpa6601_2

Schulze, S. (2003). Views on the combination of quantitative and qualitative research approaches. Progressio, 25, 8-20.

Sin, D. D., Svenson, L. W., Cowie, R. L., \& Man, S. F. (2003). Can universal access to healthcare eliminate health inequities between children of poor and non-poor families? A case study of childhood asthma in Alberta. Chest, 124(1), 51-56. doi:10.1378/chest.124.1.51

Sin, D. D., Wells, H., Svenson, L. W., \& Man, S. F. P. (2002). Asthma and COPD among Aboriginals in Alberta, Canada. Chest, 121(6), 1841-1846. doi:10.1378/chest.121.6.1841

Standing Senate Committee on Human Rights. (2007). Children: The silenced citizens. Effective implementation of Canada's international obligations with respect to the rights of children. Retrieved from http://www.parl.gc.ca/content/sen/committee/391/huma/rep/rep10apr07-e.pdf

Statistics Canada. (2013). Persons with asthma, by age and sex. Retrieved from http://www.statcan.gc.ca/tables-tableaux/sum-som/101/cst01/health49a-eng.htm

Stewart, M. J. (2000). Social support, coping, and self-care as public participation mechanisms. In M. J. Stewart (Ed.), Community nursing: Promoting Canadians' health (2nd ed., pp. 83-104). Toronto, ON: W. B. Saunders.

Stewart, M., King, M., Blood, R., Letourneau, N., Masuda, J., Anderson, S., \& Bourque Bearskin, L. (2013). Health inequities experienced by Aboriginal children with respiratory problems and their parents. Canadian Journal of Nursing Research, 45(3), 6-27. 
Supporting Parents of Aboriginal Children with Asthma: Preferences and Pilot Interventions - Miriam Stewart, Heather Castleden, Malcolm King, Nicole Letourneau, Jeffrey R. Masuda, Lisa Bourque Bearskin, Sharon Anderson, Roxanne Blood

Stewart, M., Letourneau, N., \& Kushner, K. (2010). Participatory pilot interventions for vulnerable populations: A response to Lillard. Social Science \& Medicine, 71(11), 1913-1915. doi:10.1016/j.socscimed.2010.08.024

Tashakkori, A., \& Teddlie, C. (Eds.). (2003). Handbook of mixed methods in social and behavioral research. Thousand Oaks, CA: Sage.

To, T., Dell, S., Tassoudji, M., \& Wang, C. (2009). Health outcomes in low income children with current asthma in Canada. Chronic Diseases in Canada, 29(2). Retrieved from http://www.phac-aspc.gc.ca/publicat/hpcdp-pspmc/29-2/index-eng.php\#a

Tri-Council (Canadian Institutes of Health Research, Natural Sciences and Engineering Research Council of Canada, \& Social Sciences and Humanities Research Council of Canada). (2010). Tri-Council policy statement: Ethical conduct for research involving humans. Retrieved from http://www.pre.ethics.gc.ca/pdf/eng/tcps2/TCPS_2_FINAL_Web.pdf

Tsuyuki, R. T., Sin, D. D., \& Sharpe, H. M. (2005). Management of asthma among communitybased family physicians. Journal of Asthma, 42, 163-167. doi:10.1081/jas-54615

Valentine, J., Dawar, M., \& Wardman, D. (2003). An exploration of smoking cessation and prevention interventions for Aboriginal youth. Pimatisiwin, 1, 135.

Watson, R., Castleden, H., Masuda, J., King, M., \& Stewart, M. (2012). Identifying gaps in asthma education, health promotion, and social support for Mi'kmaq families in Unama'ki (Cape Breton), Nova Scotia, Canada. Preventing Chronic Disease, 9, 120039. doi:10.5888/pcd9.120039

Weinert, C. (2003). Measuring social support: PRQ2000. In O. Strickland and C. Dilorio (Eds.), Measurement of nursing outcomes: Self care and coping (2nd ed., Vol. 3, pp. 161-172). New York, NY: Springer. 
Supporting Parents of Aboriginal Children with Asthma: Preferences and Pilot Interventions - Miriam Stewart, Heather Castleden, Malcolm King, Nicole Letourneau, Jeffrey R. Masuda, Lisa Bourque Bearskin, Sharon Anderson, Roxanne Blood

\section{Appendix A: Alberta Study Activities}

\begin{tabular}{|c|c|}
\hline $\begin{array}{l}\text { Assessment of } \\
\text { Support Needs } \\
\text { \& Intervention } \\
\text { Preferences }\end{array}$ & $\begin{array}{l}\text { Individual interviews: } 54 \text { parents from } 3 \text { Métis communities \& } 9 \text { First Nation } \\
\text { communities } \\
\text { Group interviews: } 1 \text { rural interview, } 1 \text { urban interview ( } n=25 \\
\text { parents/guardians, total, for both interviews) } \\
\text { Parents ' perceptions requested on (a) challenges requiring support; (b) } \\
\text { coping strategies, including support seeking; (c) support needs and } \\
\text { resources; (d) programs serving Aboriginal children and adolescents with } \\
\text { asthma and their parents; (e) gaps in supports and services; (f) preferences } \\
\text { for culturally appropriate support interventions; and (g) culturally } \\
\text { appropriate intervention outcomes }\end{array}$ \\
\hline $\begin{array}{l}\text { Assessment } \\
\text { Results }\end{array}$ & $\begin{array}{l}\text { Support needs: lack of support; insufficient information; concerns about risk } \\
\text { factors in home and external environment } \\
\text { Support intervention (group) preferences: support to understand and manage } \\
\text { asthma; information; advice regarding communication strategies with health } \\
\text { professionals; insights from other Aboriginal parents on managing children's } \\
\text { health conditions; culturally appropriate support, education, and community } \\
\text { awareness }\end{array}$ \\
\hline $\begin{array}{l}\text { Support } \\
\text { Intervention } \\
\text { Design \& } \\
\text { Implementation }\end{array}$ & $\begin{array}{l}\text { Intervention: support groups ( } 20 \text { parents: } 1 \text { Caucasian, } 4 \text { Métis, } 15 \text { First } \\
\text { Nation) } \\
\text { Rural }(n=8) \text { : } 8 \text { support sessions delivered by health professional via } \\
\text { Telehealth } \\
\quad \text { Topics discussed: asthma management, asthma medication, } \\
\text { communicating with health professionals, keeping homes allergen free, } \\
\text { avoiding asthma triggers, culturally relevant and safe use of traditional } \\
\text { medications } \\
\text { Aboriginal peer facilitator and Aboriginal health professional provided } \\
\text { face-to-face support following each session as needed } \\
\text { Urban }(n=12): 8 \text { support sessions held at inner city school, with discussion } \\
\text { of similar topics as rural parents as well as information on urban services } \\
\text { and supports }\end{array}$ \\
\hline $\begin{array}{l}\text { Pilot } \\
\text { Intervention } \\
\text { Impact } \\
\text { Evaluation }\end{array}$ & $\begin{array}{l}\text { Quantitative Results: support scale scores increased for both rural and urban; } \\
\text { loneliness scores decreased; increased support-seeking } \\
\text { Qualitative Results: higher asthma awareness in community; participants } \\
\text { more prepared to seek support, appreciated Telehealth, enjoyed sharing } \\
\text { meals with elders, valued information provided, wanted similar support for } \\
\text { other life challenges }\end{array}$ \\
\hline
\end{tabular}


Supporting Parents of Aboriginal Children with Asthma: Preferences and Pilot Interventions - Miriam Stewart, Heather Castleden, Malcolm King, Nicole Letourneau, Jeffrey R. Masuda, Lisa Bourque Bearskin, Sharon Anderson, Roxanne Blood

\section{Appendix B: Manitoba Study Activities}

\begin{tabular}{|c|c|}
\hline $\begin{array}{l}\text { Assessment of } \\
\text { Support Needs } \\
\text { \& Intervention } \\
\text { Preferences }\end{array}$ & $\begin{array}{l}\text { Group interviews: } 9 \text { caregivers ( } 3 \text { parents, } 5 \text { guardians/relatives, } 1 \\
\text { professional caregiver; } 7 \text { Dakota, } 1 \text { Métis, } 1 \text { Caucasian) } \\
\text { Parents '/caregivers' perceptions requested on (a) challenges requiring } \\
\text { support, (b) support needs, and (c) support intervention preferences }\end{array}$ \\
\hline $\begin{array}{l}\text { Assessment } \\
\text { Results }\end{array}$ & $\begin{array}{l}\text { Support needs: insufficient federal support of housing, overcrowded } \\
\text { multigenerational housing, air-polluting industry, poverty, concomitant risky } \\
\text { health behaviours, isolation } \\
\text { Support intervention preferences: after-school support group for adolescents } \\
\text { with asthma and allergies and their parents/guardians }\end{array}$ \\
\hline $\begin{array}{l}\text { Support } \\
\text { Intervention } \\
\text { Design \& } \\
\text { Implementation }\end{array}$ & $\begin{array}{l}\text { Intervention: Peer support group-urban after-school intervention designed } \\
\text { primarily for adolescents with asthma and allergies. Three Dakota parents ( } 2 \\
\text { mothers, } 1 \text { father) attended support group sessions; only parent/caregiver } \\
\text { findings are emphasized in this paper. }\end{array}$ \\
\hline $\begin{array}{l}\text { Pilot } \\
\text { Intervention } \\
\text { Impact } \\
\text { Evaluation }\end{array}$ & $\begin{array}{l}\text { Data collection: postintervention qualitative interviews } \\
\text { Results: support group intervention considered successful because it was } \\
\text { interactive, engaging, culturally relevant, and community led; asthma } \\
\text { information presented in context of traditional Aboriginal practices and } \\
\text { lifestyle; participants appreciated "demystification" of research }\end{array}$ \\
\hline
\end{tabular}


Supporting Parents of Aboriginal Children with Asthma: Preferences and Pilot Interventions - Miriam Stewart, Heather Castleden, Malcolm King, Nicole Letourneau, Jeffrey R. Masuda, Lisa Bourque Bearskin, Sharon Anderson, Roxanne Blood

\section{Appendix C: Nova Scotia Study Activities}

\begin{tabular}{|c|c|}
\hline $\begin{array}{l}\text { Assessment of } \\
\text { Support Needs } \\
\text { \& Intervention } \\
\text { Preferences }\end{array}$ & $\begin{array}{l}\text { Individual interviews: } 17 \text { mothers, from } 5 \text { Mi'kmaq communities } \\
\text { Parents 'perceptions requested on (a) caregiving challenges requiring } \\
\text { support, (b) coping strategies, (c) support needs and resources, and (d) gaps } \\
\text { in support programs and services for children and parents }\end{array}$ \\
\hline $\begin{array}{l}\text { Assessment } \\
\text { Results }\end{array}$ & $\begin{array}{l}\text { Support needs: allergy triggers; geographic distance to accessing support; } \\
\text { available support outside community available only in English (Mi'kmaq } \\
\text { preferred) } \\
\text { Support intervention preferences: more information and educational } \\
\text { resources; support groups; information in Mi'kmaq language; culturally } \\
\text { relevant school-based support and awareness }\end{array}$ \\
\hline $\begin{array}{l}\text { Support } \\
\text { Intervention } \\
\text { Design \& } \\
\text { Implementation }\end{array}$ & $\begin{array}{l}\text { Intervention: 2-day peer support camp for children and parents (17 } \\
\text { Mi'Kmaq mothers, same participants as in assessment interviews), with } \\
\text { Aboriginal ceremonies, cultural activities, entertainment, social support, } \\
\text { education }\end{array}$ \\
\hline $\begin{array}{l}\text { Pilot } \\
\text { Intervention } \\
\text { Impact } \\
\text { Evaluation }\end{array}$ & $\begin{array}{l}\text { Data collection: sharing circle and group interview } \\
\text { Results: connected with peers, decreased loneliness, increased asthma } \\
\text { support and education, enhanced friendships and family connections, learned } \\
\text { strategies for communicating with other community members, desire for } \\
\text { ongoing support groups }\end{array}$ \\
\hline
\end{tabular}

